\title{
MORPHOLOGICAL AND GENETIC VARIATION IN THREE POPULATIONS OF Hoplobatrachus tigerinus FROM BANGLADESH
}

\author{
M. Hasan, M. M. R. Khan and M. Sumida ${ }^{1}$ \\ Department of Fisheries Biology and Genetics, Bangladesh Agricultural University \\ Mymensingh-2202, Bangladesh
}

\begin{abstract}
In order to investigate the morphological and genetic variation of Indian bullfrog Hoplobatrachus tigerinus, live samples were collected from three populations located in Khulna (southern part), Char Nilokhia and Netrokona (central part) in Bangladesh. The proportions of head length and head width (HL : HW), eye length and tympanum diameter (EL:TD), head length and snout length (HL : SL), internarial space and interorbital distance (IN:IOD) and internarial space and distance from nostril to tip of snout (IN:NS) of the Khulna population were significantly higher $(p<0.05)$ than those of the other two populations. For allozyme study, 4 enzymes were screened, where 5 presumptive scorable loci were identified. The highest values of mean proportion of polymorphic loci $(<0.95)$, mean number of alleles per locus and mean number of heterozygous loci per individual were observed in the Khulna population $(60 \%, 1.60$ and $14.0 \%$ respectively). The pairwise genetic differentiation $\left(F_{S T}\right.$ and Nei's $\left.D\right)$ was the highest $(0.279$ and 0.157 , respectively) between the Khulna and Netrokona populations. The UPGMA dendrogram showed two clusters i.e. the Char Nilokhia and Netrokona populations formed one cluster, whereas the Khulna population alone made another cluster. These results suggested that the Khulna population diverged morphologically and genetically from the other two populations probably due to its geographical distance. Further extensive study will be necessary for elucidating the whole aspects of differentiation in H. tigerinus from Bangladesh.
\end{abstract}

Key words : Morphology, Allozyme analysis, Geographical distance, H. tigerinus

\section{INTRODUCTION}

Bangladesh is enriched with aquatic biodiversity (DoF, 2007), and contains a number of diverse ecosystems supporting roughly 113 species of mammals, 628 species of birds, 126 species of reptiles, 22 species of amphibians, 708 species of freshwater and marine fish, about 400 species of mollusks, and 140 species of bees and wasps, but many of them are on the nation's list of threatened animals (Reza, 2007). Among these amphibian species, Hoplobatrachus tigerinus (previously called it Rana tigerina) was an important group, and it is available in many Asian countries such as India, Pakistan, Nepal, Bhutan, Myanmar,

\footnotetext{
${ }^{1}$ Institute of Amphibian Biology, Graduate School of Science, Hiroshima University, Japan
} 
Thailand, Malaysia and Indonesia (Frost, 2007). Once H. tigerinus species was available in the diversified water bodies of Bangladesh. Its leg is an important delicious food item to many people especially tribal people in Europe and Asia. Some people of Bangladesh used to catch and export frog legs to abroad, but indiscriminate harvesting of frogs had brought a bad impact on the natural ecosystem which pursued the government of Bangladesh to impose a ban on this frog collection, harvesting and processing. It plays an important role in controlling ecosystem, so, it is important to protect the species. Thus, morphological and genetic variation of different natural stocks of the population must be studied. In India, the adverse impact of uncontrolled harvesting of frogs, specifically $H$. tigerinus, from rice-fields and wet-lands, where they protect crops by devouring damaging insects, led to a ban on collecting frogs during the breeding season (Husain and Rahman, 1978).

Research work on frogs of Bangladesh has started in last decade (Islam, 2000 ; Khan et al., 2002; Islam et al., 2008a, b; Alam et al., 2008). The culture, breeding and genetics of frogs have been observed in many frog species. Using allozyme technique, many studies on anuran distributed in Japan and adjacent countries have been reported by Nishioka and her collaborators. The genetic differences in R. limnocharis (= F. limnocharis) (Nishioka and Sumida, 1990), Hyla japonica (Nishioka et al., 1990), R. japonica (Sumida and Nishioka, 1994), R. nigromaculata and R. brevipoda (Nishioka et al., 1992), and R. rugosa (Nishioka et al., 1993) have been reported by allozyme techniques. The purpose of this study was to identify the morphological and genetic variation of this particular amphibian species $(H$. tigerinus) in three regions viz. Khulna (southern part), Char Nilokhia and Netrokona (central part) of Bangladesh by allozyme analysis.

\section{MATERIALS AND METHODS}

Live frogs of $H$. tigerinus were collected from three different geographical localities, i.e. Khulna, Char Nilokhia and Netrokona during the months of March to May, 2007. A total of 10 specimens were collected from each locality. The distance between Khulna and Char Nilokhia was $200 \mathrm{~km}$, whereas Netrokona and Char Nilokhia was only $30 \mathrm{~km}$. The muscle and liver samples were taken from each individual and stored at $-21^{\circ} \mathrm{C}$ until use. Details of the sampling localities, number of specimen and date of collection are given in Table 1.

Table 1. Collecting locality, sample size and date of collection of three populations of $H$. tigerinus

\begin{tabular}{ccccc}
\hline Population No. & Locality & No. of individual & Date of collection \\
\hline 1 & Khulna & 10 & March 13, 2007 \\
2 & Char Nilokhia & 10 & April 14, 2007 \\
3 & Netrokona & 10 & May 12, 2007 \\
\hline
\end{tabular}


The morphometric data were recorded using normal centimeter scale, divider and forceps, recorded to the nearest centimeter. The morphometric characters viz., snout-vent length (SVL), hind limb length (HLL), head length (HL), head width (HW), thigh length (THIGHL), tibia length (TL), internarial space (IN), inter orbital distance (IOD), eye length (EL), tympanum diameter (TD), snout length (SL), distance from nostril to tip of snout (NS), distance from back of mandible to back of eye (MFE), distance from back of mandible to front of eye (MBE), snout tympanum length (STL), mouth angle snout length (MSL), nostril tympanum length (NTL), distance from front of eyes to nostril (EN), tympanum eye length (TEL), distance from back of mandible to nostril (MN), maximum width of upper eyelid (UEW), hand length (HAL), forelimb length (FLL), lower arm length (LAL), foot length (FOL), length of tarsus and foot (TFOL), third finger length (3FL), first finger length (1FL), fourth toe length (4TL), inner metatarsal tubercle length (IMTL) and inner toe length (ITL). The thirty-one morphometric characters were measured following the conventional methods described by Hubbs and Lagler (1958) with the help of a slide caliper.

In this experiment, horizontal starch gel electrophoresis was done following the methods by Shaw and Prasad (1970). Electrophoresis was conducted using amine-citrate buffer (C.A. 6) (Clayton and Tretaik, 1972). After electrophoresis, the gel slices (about $1 \mathrm{~mm}$ thickness) were histochemically stained for different enzymes as described in Aebersold et al. (1987). Non-parametric statistical analyses were used in all the comparisons (Zar, 1996). Differences in morphometric characters among populations were analyzed using the Kruskal-Wallis non-parametric analysis of variance (ANOVA). For instances, where significant differences between populations were detected, a non-parametric post hoc test (Zar, 1996) was conducted. Allelic frequencies were calculated directly from observed genotypes. The distribution of observed genotypes was calculated from the HardyWeinberg equilibrium using a chi-square $\left(\chi^{2}\right)$ test for allozyme system. When the most common allele existed in a frequency of less than 0.95 at a given locus, it was regarded as polymorphic. The mean proportion of heterozygous loci per individual, mean proportion of polymorphic loci per population, and average number of alleles per locus were calculated so as to show the extent of genetic variability for each population (Lewontin, 1974). Expected heterozygosity $(\mathrm{He})$ and observed heterozygosity $(\mathrm{Ho})$ were examined according to Nei and Roychoudhury (1973). Genetic distance $(D)$ value was calculated using Nei's formula (Nei, 1972).

\section{RESULTS}

Thirty one morphometric characters recorded from the samples of three populations of $H$. tigerinus are shown in Table 2. Average values of morphometric characters showed slight variation among three populations. Different proportions of morphometric characteristics (SVL : HLL, HL : HW, THIGH : TL, IN : IOD, EL : TD, HL : SL, IN : NS and MFE : MBE) of H. tigerinus are given in Table 3 . The proportions of seven morphometric characters (HL : HW, THIGH : TL, IN : IOD, EL : TD, HL : SL, IN : NS and MFE : MBE) of all populations of $H$. tigerinus were significantly different $(p<0.05)$ from each other. The proportion of head length-head width (HL : HW), eye length-tympanum diameter (EL : 
TD), head length-snout length (HL : SL), internarial space-interorbital distance (IN : IOD) and internarial space-distance from nostril to tip of snout (IN : NS) of the Khulna population was significantly higher $(\mathrm{p}<0.05)$ than those of the rest two populations. Thigh length-tibia length (THIGH : TL) of the Char Nilokhia population was higher than those of the other populations.

Table 2. Mean measurement values of thirty-one morphometric characters in three populations of $H$. tigerinus. $n=10$ for each population.

\begin{tabular}{|c|c|c|c|}
\hline $\begin{array}{c}\text { Morphometric } \\
\text { character }\end{array}$ & $\begin{array}{c}\text { Khulna } \\
(\text { Mean } \pm \text { SD) }\end{array}$ & $\begin{array}{c}\text { Char Nilokhia } \\
(\text { Mean } \pm \text { SD) }\end{array}$ & $\begin{array}{c}\text { Netrokona } \\
(\text { Mean } \pm \text { SD) }\end{array}$ \\
\hline SVL & $10.59 \pm 1.47$ & $12.33 \pm 0.79$ & $11.55 \pm 1.35$ \\
\hline HL & $4.68 \pm 1.82$ & $4.44 \pm 0.26$ & $4.26 \pm 0.29$ \\
\hline HW & $4.14 \pm 0.48$ & $4.24 \pm 0.58$ & $4.53 \pm 0.32$ \\
\hline STL & $2.81 \pm 0.14$ & $3.26 \pm 0.21$ & $3.00 \pm 0.00$ \\
\hline MSL & $4.22 \pm 1.95$ & $3.76 \pm 0.79$ & $3.68 \pm 0.11$ \\
\hline NS & $0.52 \pm 0.11$ & $0.72 \pm 0.05$ & $0.67 \pm 0.05$ \\
\hline SL & $1.61 \pm 0.36$ & $1.94 \pm 0.12$ & $1.72 \pm 0.09$ \\
\hline NTL & $1.75 \pm 1.05$ & $2.94 \pm 0.25$ & $2.73 \pm 0.52$ \\
\hline EN & $0.96 \pm 0.06$ & $1.15 \pm 0.16$ & $1.01 \pm 0.04$ \\
\hline TEL & $0.51 \pm 0.05$ & $0.52 \pm 0.08$ & $0.50 \pm 0.00$ \\
\hline $\mathrm{MN}$ & $2.92 \pm 1.06$ & $3.65 \pm 0.29$ & $3.81 \pm 0.33$ \\
\hline MFE & $2.67 \pm 0.26$ & $2.95 \pm 0.15$ & $2.96 \pm 0.08$ \\
\hline MBE & $2.21 \pm 0.22$ & $2.08 \pm 0.19$ & $2.05 \pm 0.08$ \\
\hline IN & $0.59 \pm 0.05$ & $0.52 \pm 0.13$ & $0.68 \pm 0.04$ \\
\hline EL & $0.99 \pm 0.03$ & $1.02 \pm 0.07$ & $1.01 \pm 0.04$ \\
\hline IOD & $0.63 \pm 0.15$ & $0.66 \pm 0.14$ & $1.05 \pm 0.08$ \\
\hline UEW & $0.48 \pm 0.31$ & $0.67 \pm 0.04$ & $0.52 \pm 0.04$ \\
\hline HAL & $2.03 \pm 0.09$ & $2.95 \pm 0.94$ & $2.18 \pm 0.17$ \\
\hline FLL & $2.05 \pm 0.15$ & $2.59 \pm 0.29$ & $2.05 \pm 0.15$ \\
\hline LAL & $2.42 \pm 0.16$ & $2.67 \pm 0.24$ & $2.28 \pm 0.12$ \\
\hline HLL & $15.52 \pm 2.80$ & $18.41 \pm 0.83$ & $17.26 \pm 1.43$ \\
\hline THIGH & $4.28 \pm 0.78$ & $5.22 \pm 0.28$ & $4.38 \pm 0.44$ \\
\hline $\mathrm{TL}$ & $5.23 \pm 0.61$ & $6.06 \pm 0.36$ & $5.46 \pm 0.44$ \\
\hline TFOL & $7.21 \pm 0.46$ & $8.03 \pm 0.06$ & $8.16 \pm 0.51$ \\
\hline $3 F L$ & $1.10 \pm 0.20$ & $1.48 \pm 0.12$ & $1.35 \pm 0.22$ \\
\hline $1 \mathrm{FL}$ & $0.61 \pm 0.16$ & $1.00 \pm 0.04$ & $0.90 \pm 0.22$ \\
\hline $4 \mathrm{TL}$ & $3.13 \pm 1.05$ & $4.06 \pm 0.67$ & $4.00 \pm 0.17$ \\
\hline IMTL & $0.50 \pm 0.00$ & $0.49 \pm 0.02$ & $0.50 \pm 0.06$ \\
\hline FOL & 00 & 00 & 00 \\
\hline
\end{tabular}


Table 3. Morphometric proportions in three populations of $H$. tigerinus. Values of the parameter in each column with different superscripts (a, b \& c) differed significantly $(\mathrm{p}<0.05)$

\begin{tabular}{l|c|c|c|c|c|c|c|c}
\hline Population & SVL:HLL & HL:HW & THIGH:TL & IN:IOD & EL:TD & HL:SL & IN:NS & MFE:MBE \\
\hline Char & $0.670 \pm 0.01^{\mathrm{a}}$ & $1.047 \pm 0.01^{\mathrm{b}}$ & $0.861 \pm 0.01^{\mathrm{a}}$ & $0.788 \pm 0.01^{\mathrm{b}}$ & $1.109 \pm 0.01^{\mathrm{c}}$ & $2.289 \pm 0.01^{\mathrm{c}}$ & $0.722 \pm 0.01^{\mathrm{c}}$ & $1.418 \pm 0.01^{\mathrm{b}}$ \\
Nilokhia & & & & & & & & \\
Netrokona & $0.669 \pm 0.01^{\mathrm{a}}$ & $0.940 \pm 0.01^{\mathrm{c}}$ & $0.802 \pm 0.01^{\mathrm{b}}$ & $0.648 \pm 0.00^{\mathrm{c}}$ & $1.247 \pm 0.01^{\mathrm{b}}$ & $2.480 \pm 0.01^{\mathrm{b}}$ & $1.010 \pm 0.01^{\mathrm{b}}$ & $1.444 \pm 0.01^{\mathrm{a}}$ \\
Khulna & $0.682 \pm 0.01^{\mathrm{a}}$ & $1.130 \pm 0.01^{\mathrm{a}}$ & $0.818 \pm 0.01^{\mathrm{b}}$ & $0.937 \pm 0.00^{\mathrm{a}}$ & $1.800 \pm 0.01^{\mathrm{a}}$ & $2.900 \pm 0.01^{\mathrm{a}}$ & $1.130 \pm 0.01^{\mathrm{a}}$ & $1.208 \pm 0.01^{\mathrm{c}}$ \\
\hline
\end{tabular}

The enzyme analyzed, E.C. number, abbreviation of enzyme and the buffer system used for horizontal starch-gel electrophoresis are shown in Table 4. Allele frequencies were calculated directly from genotypes at 5 loci for each population. Among the five loci observed, three loci (Gpi-2, Mdh-1, and Pgm) were polymorphic, and the $L d h-1$ and $L d h-2$ loci were invariant. The Gpi-2, Mdh-1 and Pgm loci showed allelic frequencies of $a=0.250$ and $b=0.750, a=0.900$ and $b=0.100$, and $a=0.850$ and $b=0.150$ for the Khulna population, $a=0.700$ and $b=0.300, a=1.000, a=0.800$ and $b=0.200$ for the Char Nilokhin population, and $a=1.000, a=0.800$ and $b=0.200$, and $a=0.650$ and $b=0.350$ for the Netrokona population, respectively (Table 5, Figs. 1 and 2). The chi-square test was done in all the cases of polymorphic loci between observed genotypes and expected genotypes, based on Hardy-Weinberg equilibrium. In case of three populations of $H$. tigerinus, the Gpi-2 locus was shown to be significant $(p \leq 0.01)$ in fitness test of Hardy-Weinberg equilibrium. The observed number of alleles $(\mathrm{Na}=1.60)$, the proportion of heterozygous loci per population $(14.0 \%)$ and the proportion of polymorphic loci per population $(60.0 \%)$ were higher in the Khulna population than those of the other two populations (Table 6). The fixation index $\left(F_{S T}\right)$ and gene flow $\left(N_{m}\right)$ are given in Table 7 . The fixation index $\left(F_{S T}\right)$ and the gene flow $\left(N_{m}\right)$ overall three populations are 0.219 and 0.889 , respectively. In the pair-wise analysis, the highest $F_{S T}$ value and the lowest $N_{m}$ value were estimated to be 0.279 and 0.647 , respectively, between the Khulna and Netrokona populations (Table 7).

Table 4. Enzyme and buffer system used for allozyme analysis

\begin{tabular}{l|c|c|c|c}
\hline \multicolumn{1}{c|}{ Enzyme (Abbreviation) } & Locus & $\begin{array}{c}\text { Enzyme } \\
\text { pattern }\end{array}$ & E.C. Number & $\begin{array}{c}\text { Buffer } \\
\text { system* }\end{array}$ \\
\hline Glucose-6-phosphate isomerase (GPI) & Gpi-2 & Dimer & 5.3 .1 .9 & C.A. 6 \\
Lactate dehydrogenase (LDH) & $L d h-1$ & Tetramer & 1.1 .1 .27 & C.A. 6 \\
& $L d h-2$ & & & \\
Malate dehydrogenase (MDH) & $M d h-1$ & Dimer & 1.1 .1 .37 & C.A. 6 \\
Phosphoglucomutase (PGM) & $P g m$ & Monomer & 5.4 .2 .2 & C.A. 6 \\
\hline
\end{tabular}

* C.A. 6 represents the amine-citrate $\mathrm{pH} 6$ buffer 
Table 5. Allele frequency at five presumptive loci of three H. tigerinus populations

\begin{tabular}{|c|c|c|c|c|}
\hline \multicolumn{5}{|c|}{ Allele frequency } \\
\hline Locus & Allele & Khulna & Char Nilokhia & Netrokona \\
\hline \multirow[t]{2}{*}{ Gpi-2 } & $a$ & 0.250 & 0.700 & 1.000 \\
\hline & $b$ & 0.750 & 0.300 & - \\
\hline$P$ & & $0.009^{*}$ & $0.001^{*}$ & - \\
\hline Ldh-1 & $a$ & 1.000 & 1.000 & 1.000 \\
\hline$L d h-2$ & $a$ & 1.000 & 1.000 & 1.000 \\
\hline \multirow[t]{2}{*}{$M d h-1$} & $a$ & 0.900 & 1.000 & 0.800 \\
\hline & $b$ & 0.100 & - & 0.200 \\
\hline$P$ & & $0.808^{N S}$ & - & 0.146 NS \\
\hline \multirow[t]{2}{*}{$P g m$} & $a$ & 0.850 & 0.800 & 0.650 \\
\hline & $b$ & 0.150 & 0.200 & 0.350 \\
\hline$P$ & & $0.655^{\text {NS }}$ & $0.500^{\mathrm{NS}}$ & $0.880^{\mathrm{NS}}$ \\
\hline
\end{tabular}

$\mathrm{p}$ : Probability of Chi-square value. * Significant level : $\mathrm{p} \leq 0.01$. NS Non-significant $\mathrm{p} \leq 0.1$

Table 6. Genetic variabilities at 5 loci of three $H$. tigerinus populations

\begin{tabular}{|c|c|c|c|c|c|c|}
\hline \multirow[t]{2}{*}{ Population } & \multirow{2}{*}{$\begin{array}{c}\text { Mean proportion } \\
\text { of polymorphic } \\
\text { loci }{ }^{*}(\%)\end{array}$} & \multirow{2}{*}{$\begin{array}{c}\text { Mean number } \\
\text { of alleles per } \\
\text { locus }(\mathrm{Na})\end{array}$} & \multirow{2}{*}{$\begin{array}{l}\text { Mean proportion of } \\
\text { heterozygous loci per } \\
\text { individual }(\%)\end{array}$} & \multicolumn{3}{|c|}{ Heterozygosity } \\
\hline & & & & $H_{o}$ & $H_{e}$ & $H_{o} / H_{e}$ \\
\hline Khulna & 60.0 & 1.60 & 14.0 & 0.12 & 0.17 & 0.71 \\
\hline Netrokona & 40.0 & 1.40 & 12.0 & 0.08 & 0.16 & 0.52 \\
\hline Char Nilokhia & 40.0 & 1.40 & 14.0 & 0.140 & 0.16 & 0.88 \\
\hline Average & 46.7 & 1.47 & 13.3 & 0.11 & 0.16 & 0.67 \\
\hline
\end{tabular}

* $\mathrm{p} \leq 0.95$

Table 7. Fixation index $\left(F_{S T}\right)$ and gene flow $\left(N_{m}\right)$ in three $H$. tigerinus populations

\begin{tabular}{l|c|c}
\hline \multicolumn{1}{c|}{ Pairwise } & $F_{S T}$ & $N_{m}{ }^{*}$ \\
\hline Khulna-Char Nilokhia & 0.122 & 1.802 \\
Char Nilokhia-Netrokona & 0.092 & 2.484 \\
Khulna-Netrokona & 0.279 & 0.647 \\
Overall & 0.219 & 0.890 \\
\hline
\end{tabular}

${ }^{*} \mathrm{~N}_{\mathrm{m}}=$ Gene flow estimated from $\mathrm{F}_{\mathrm{ST}}=0.25\left(1-\mathrm{F}_{\mathrm{ST}}\right) / \mathrm{F}_{\mathrm{ST}}$

Table 8. Nei's (1972) original measures of genetic identity (above diagonal) and genetic distance (below diagonal) estimated among three H. tigerinus populations based on 5 loci

\begin{tabular}{lcccc}
\hline \multicolumn{1}{c|}{ Population } & Khulna & Char Nilokhia & Netrokona \\
\hline Khulna & - & 0.94 & 0.854 \\
Char Nilokhia & 0.052 & - & 0.964 \\
Netrokona & 0.157 & 0.036 & - \\
\hline
\end{tabular}



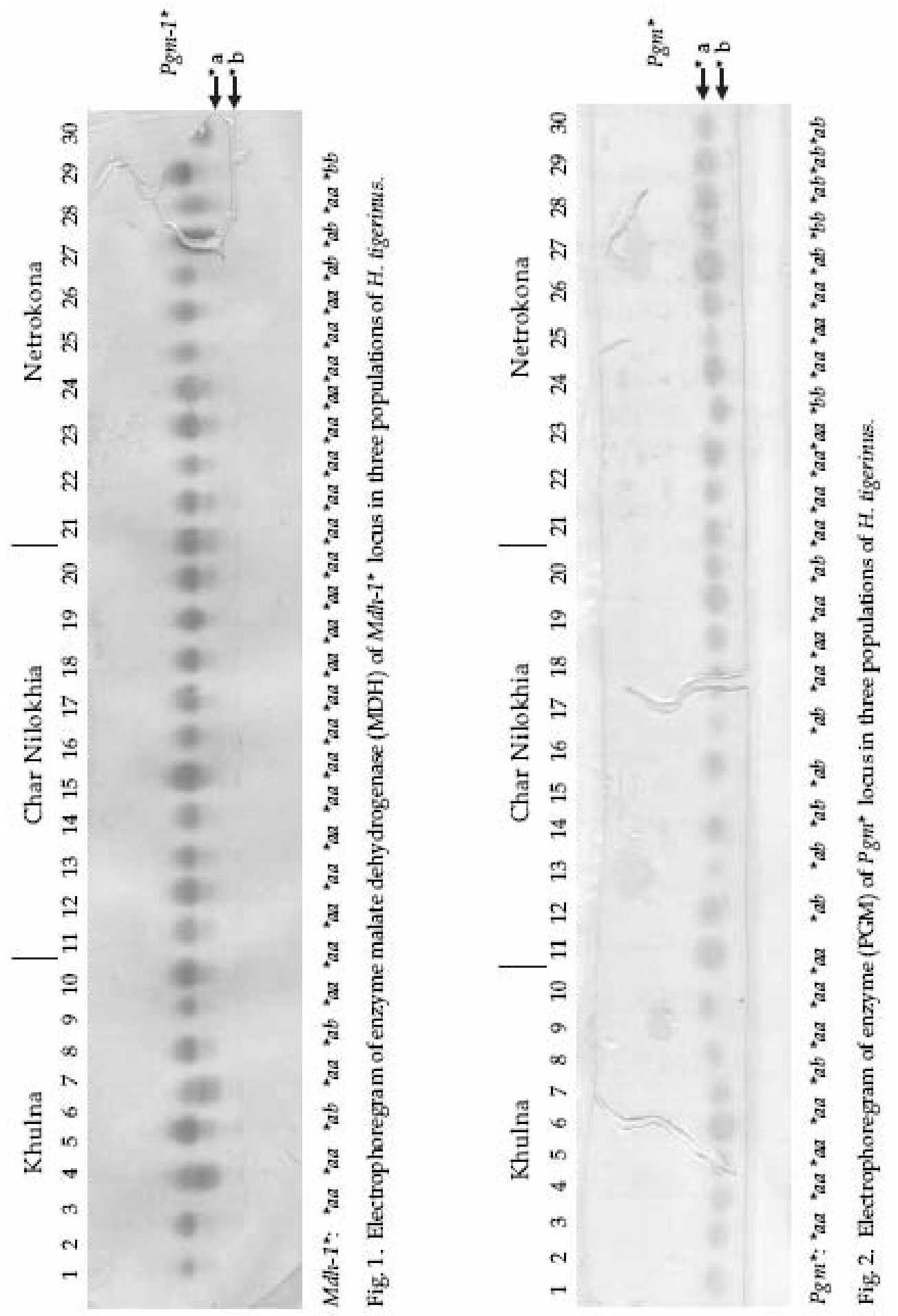


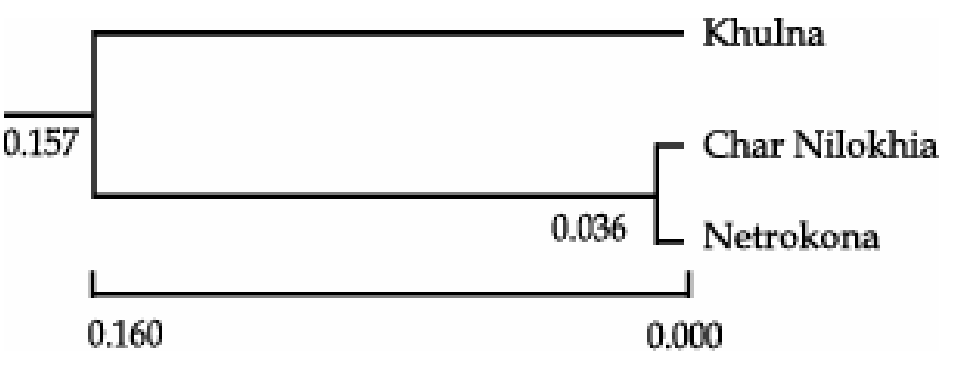

Fig. 3. Nei's (1972) UPGMA dendrogram showing the genetic distance (D) among three populations of $H$. tigerinus

The genetic distance $(D)$ (Nei, 1972) varied from 0.036 to 0.157 among three populations. The minimum value (0.036) was observed between the Char Nilokhia and Netrokona populations, whereas the highest value (0.157) was observed between the Khulna and Netrokona populations (Table 8, Fig. 3).

\section{DISCUSSION}

Mean snout-vent length of the species recorded as $12.33 \mathrm{~cm}$ in the Char Nilokhia population, $11.55 \pm 1.35 \mathrm{~cm}$ in the Netrokona population, and $10.59 \pm 1.47 \mathrm{~cm}$ in the Khulna population may be explained as the environmental effects. These may be due to the influence of photoperiod, day-length and feeding schedule on tadpole growth and development (Wright et al., 1988). The longest head length was in the Khulna population with the value of $4.68 \pm 1.82 \mathrm{~cm}$, whereas the shortest was $4.26 \pm 0.29 \mathrm{~cm}$ in the Netrokona population. Notwithstanding, these deviations were found due to the anthropological and other genetic factors affected on their growth, which was supported by Hirata et al. (1991). Bruneau and Magnin (1980) observed that Rana catesbeiana might attain a length of $10.50 \mathrm{~cm}$ and its growth depends on the temperature, availability of food and fecundity.

Among five presumptive loci, only three loci (Gpi-2, Mdh-1 and Pgm) were found to be polymorphic in all populations. The polymorphic loci for all populations had two alleles ( $a$ and $b$ ). Nishioka et al. (1993) found that the mean proportion of polymorphic loci in 40 populations of $R$. rugosa was $31.1 \%$, which was much lower than the value $(46.7 \%)$ obtained in the present study. The H. tigerinus populations clearly showed a higher level of polymorphism than the above-mentioned $R$. rugosa populations. The mean number of alleles per locus ranged from 1.40 to 1.60 (average 1.47), which was a little bit higher than the value (1.42) obtained by Nishioka et al. (1993) in $R$. rugosa. In contrast, this value (1.47) was lower than that (2.00) obtained by Nishioka et al. (1987) in three genera Buergeria, Rhacophorus and Polypedates, and by Khan et al. (2002) in H. tigerinus. These variations might be due to different sampling size and the difference in the number of loci observed. The mean proportion of heterozygous loci per individual ranged from $12.0 \%$ to $14.0 \%$ (average $13.3 \%$ ), which was similar to those obtained by Sumida and Nishikoka (1996). The mean proportion of polymorphic loci of $R$. ornativentris and $R$. 
rugosa were $14.4 \%$ and $11.3 \%$, respectively. The observed heterozygosity $\left(H_{0}\right)$ ranged from 0.08 to 0.14 (average 0.11 ) was higher than that $(0.10)$ reported by Raginski and Babik (2000) in R. arvalis. The expected heterozygosity $\left(H_{e}\right)$ was found to be 0.16 in the present study, which was similar to those obtained by Rafiniski and Babik (2000) and Khan et al. (2002). However, the present value was much higher than that obtained by Formas and Breva (2000). The level of heterozygosity was related with the size of populations within a species, although higher heterozygosity $\left(H_{0}\right)$ value is necessary for breeding program. The highest observed and expected heterozygosities $\left(H_{o}=0.14\right.$ and $\left.H_{e}=0.17\right)$ were observed in the Char Nilokhia population and the Khulna population, respectively.

The co-efficient of gene differentiation $\left(F_{S T}\right)$ in all three $H$. tigerinus populations were examined (Nei, 1972) and $F_{S T}$ was found to be 0.219 , which indicated that the population contained slight genetic differentiation, and that the number of migrated individuals from one population to another was high $\left(N_{m}=0.890\right)$. The overall $F_{S T}$ value $(0.219)$ obtained in $H$. tigerinus populations was lower than that $(0.306)$ obtained in $R$. ornativentris populations (Sumida and Nishioka, 1996). The observed genetic distance between the Khulna population and the other populations might be due to the geographical distances. Based on Nei's (1972) genetic distance ( $D$-value), the UPGMA dendrogram showed that the three populations could be grouped into two clusters as shown in the dendrogram (Fig. 3). First cluster contained the Khulna population alone, and separated from second one by $D=0.157$, whereas the second cluster comprised of the Char Nilokhia and Netrokona populations. In the second cluster, the Char Nilokhia population differentiated from the Netrokona population by $D=0.036$. Islam et al. (2008a, b) reported that the mean genetic distance between the medium and small types of the Fejervarya limnocharis complex was 0.782, and suggested that these two types are distinct species. The genetic distance (0.157) observed between two clusters (the Khulna population and the Char Nilokhia and Netrokona populations) was smaller than that between two types of the Fejervary limnocharis complex mentioned above. Among the Dicroglossus species from the Mediterranean area, genetic distances were reported to be 0.17 - 1.04 (Zangari et al., 2006). These differentiations might be due to different species or geographical variations. The genetic distance $(D)$ ranged from 0.036 to 0.157 among the three populations of $H$. tigerinus. The minimum genetic distance $(0.036)$ was observed between the Char Nilokhia and Netrokona populations, while the maximum value (0.157) was found between the Khulna and Netrokona populations (Table 8). Nei (1972) stated that values of $D$ for inter-species comparison, sub-species and local races are 1.0, 0.1 and 0.01 , respectively, while Ayala (1975) proposed that the $D$ value for sub-species is 0.20 . The present findings assumed that $H$. tigerinus populations might be under local races. Extensive genetic divergence might establish reproductive isolation that reflects further accumulation of genetic differentiation at many loci over a long period of time (Ferguson, 2002; Sites and Marshall, 2003, 2004). However, further extensive research works on genetic variability of the frog populations of many localities will be necessary for elucidating the whole aspects of differentiation of $H$. tigerinus in Bangladesh using different molecular markers i.e. RFLP (Restriction Fragment Length Polymorphism), RAPD (Random Amplified Polymorphic DNA), microsatellite DNA markers etc. 


\section{REFERENCES}

Aebersold, P. B., Winans, G. A., Teel, D. J., Milner, G. B. and Utter, F. M. 1987. Manual for starch gel electrophoresis: a method for the detection of genetic variation. NOAA Technical Report NMFS, 61: 1-19.

Alam, M. S., Igawa, T., Khan, M. M. R., Islam, M. M., Kuramoto, M., Matsui, M., Kurabayashi, A. and Sumida, M. 2008. Genetic divergence and evolutionary relationships in six species of genera Hoplobatrachus and Euphlyctis (Amphibia: Anura) from Bangladesh and other Asian countries revealed by mitochondrial gene sequences. Mol. Phylogenet. Evol., 48: 515-527.

Ayala, F. J. 1975. Genetic differentiation during the speciation process. Evol. Biol., 8: 1-78.

Bruneau, M. and Magnin, E. 1980. Larval development in Rana catesbeiana Shaw (Amphibia: Anura) of the Laurentian region of Quebec. Can. J. Zool., 58(2): 169-174.

Clayton, J. W. and Tretiak, D. N. 1972. Amine-citrate buffers for $\mathrm{pH}$ control in starch gel electrophoresis. Can. J. Fish. Aquat. Sci., 29: 1169-1172.

DoF, 2007. Saranica, Matshya Pakhya Sankalan-2007. Ministry of Fisheries and Livestock. The Goverenment of Peoples Republic in Bangladesh, Dhaka. 130 pp.

Ferguson, J. W. H. 2002. On the use of genetic divergence for identifying species. Bio. J. Linn. Soc., 75: 509-516.

Formas, J. R. and Breva, L. M. 2000. Population genetics of the Chilean frog Batrachyla leptopus (leptodactylidae). Genet. Mol. Biol., 23(1): 232-243.

Frost, D. R. 2007. Amphibian Species of the World: an Online Reference. Version 5.0 (25 October, 2007). American Museum of Natural History, New York, Electronic Database accessible at http://research.amnh.org/herpetology/amphibia/index. php.

Hirata, J. S. Nishikawa and Sasaki, F. 1991. Morphological and biochemical changes of anuran notochord during the development of Rana japonica. Zool Sci., 8(6): 1076.

Hubbs, C. L. and Lagler, K. L. 1958. Fishes of the great lake region, $2^{\text {nd }}$ ed. Cranbrook Institute of Scientific Bulletin, 26: 1-213.

Husain, K. Z. and Rahman, M. M. 1978. The amphibian fauna of Bangladesh. Bangladesh J. Zool., 6(2): 157-158.

Islam, M. A. 2000. Intensive culture of bull frog Hoplobatrachus tigrina. Final report of Bangladesh Agricultural University Research System. 1-37 pp.

Islam, M. M., Khan, M. M. R., Djong, T. H., Alam M. S. and Sumida, M. 2008a. Genetic differentiation of the Fejervarya limnocharis complex from Bangladesh and other Asian countries Elucidated by allozyme analyses. Zool. Sci., 25: 261-272 .

Islam, M. M., Kurose, N., Khan, M. M. R., Nishizawa, T., Kuramoto, M., Alam, M. S., Hasan, M., Kurniawan, N., Nishioka, M. and Sumida, M. 2008b. Genetic divergence and reproductive isolation in the genus Fejervarya (Amphibia: Anura) from Bangladesh inferred from morphological observations, crossing experiments, and molecular analyses. Zool. Sci., 25: 1084-1105.

Khan, M. M. R., Alam, M. S., Sarder, M. R. I., Bhuiyan, M. M. H. and Sumida, M. 2002. Study on genetic variation of frogs in Bangladesh using allozyme marker. Bangladesh J. Fish., 25(1-2): 3546.

Lewontin, R. C. 1974. The Genetic Basis of Evolutionary Change. Columbia University Press, New York.

Nei, M. 1972. Genetic distance between populations. Am. Nat., 106: 283-292. 
Nei, M. and Roychoudhury, A. K. 1973. Probability of fixation and mean fixation time of an over dominant mutation. Genetics, 74: 371-380.

Nishioka, M. and Sumida, M. 1990. Differentiation of Rana limnocharis and two allied species elucidated by electrophoretic analyses. Sci. Rep. Lab. Amphibian Biol., Hiroshima Univ., 10: 125-154.

Nishioka, M., Kodama, Y., Sumida, M. and Ryuzaki, M. 1993. Systematic evolution of 40 populations of Rana rugosa distributed in Japan elucidated by electrophoresis. Sci. Rep. Lab. Amphibian Biol., Hiroshima Univ., 12: 83-131.

Nishioka, M., Sumida, M. and Borkin, L. J. 1990. Biochemical differentiation of the genus Hyla distributed in the Far East. Sci. Rep. Lab. Amphibian Biol., Hiroshima Univ., 10: 93-124.

Nishioka, M., Sumida, M. and Ohtani, H. 1992. Differentiation of 70 populations in the Rana nigromaculata group by the method of electrophoretic analyses. Sci. Rep. Lab. Amphibian Biol., Hiroshima Univ., 11: 1-70.

Nishioka, M., Sumida, M., Ohta, S. and Suzuki, H. 1987. Speciation of three allied genera, Buergeria, Rhacophorus and Polypedates, elucidated by the method of electrophoretic analysis. Sci. Rep. Lab. Amphibian Biol., Hiroshima Univ., 9: 53-96.

Raginski, J. and Babik, W. 2000. Genetic differentiation among Northern and Southern populations of the moor frog Rana arvalis Nilsson in central Europe. Heredity., 84(5): 610-618.

Reza, A. H. M. A. 2007. Destination Bangladesh: From the Himalayas to the Bay of Bengal. Travelogue Iguana., 14(2): 107-115.

Shaw, C. R. and Prasad, R. 1970. Starch gel electrophoresis of enzymes-a compilation of recipes. Biochem. Genet., 4: 297-330.

Sites, J. W. and Marshall, J. C. 2003. Delimitation species: a renaissance issue in systemic biology. Trends Ecol. Evol., 18: 462-470.

Sites, J. W. and Marshall, J. C. 2004. Operational criteria for delimiting species. Annu. Rev. Ecol. Evol. Syst., 35: 199-227.

Sumida, M. and Nishioka, M. 1994. Genetic differentiation of the Japanese brown frog, Rana japonica, elucidated by electrophoretic analysis of enzymes and blood proteins. Sci. Rep. Lab. Amphibian Biol., Hiroshima Univ., 13: 137-171.

Sumida, M. and Nishioka, M. 1996. Genetic variation and population divergence in the mountain brown frog, Rana ornativentris. Zool Sci., 13: 537-549.

Wright, M. L., Jorey, S. T., Myers, Y. M., Fieldstad, M. L., Paquette, C. M. and Clark, M. B. 1988. Influence of photoperiod, day-length and feeding schedule on tadpole growth and development. Dev. Growth, Differ., 30(3): 315-323.

Zangari, F., Cimmaruta, R. and Nascetti, G. 2006. Genetic relationship of the western Mediterranean painted frogs based on allozyme and mitochondrial markers: Revolutionary and taxonomic inferences (Amphibia, Anura, Discoglossidae). Bio. J. Linn. Soc., 87: 515-536.

Zar, J. A. 1996. Biostatistical Analyses. $3^{\text {rd }}$ edn. Prentice Hall, Engle Wood Cliffs, New Jersey, 15-20 pp. 